\title{
Molecular Design, Structural Analysis and Antifungal Activity of Derivatives of Peptide CGA-N46
}

\author{
Rui-Fang Li ${ }^{1}$ Zhi-Fang Lu ${ }^{1}$ Ya-Nan $\mathrm{Sun}^{1} \cdot$ Shi-Hua Chen ${ }^{1}$ Yan-Jie Yi ${ }^{1}$. \\ Hui-Ru Zhang ${ }^{1} \cdot$ Shuo-Ye Yang ${ }^{1}$ Guang-Hai Yu ${ }^{1} \cdot$ Liang Huang $^{1} \cdot$ \\ Chao-Nan $\mathrm{Li}^{1}$
}

Received: 28 September 2015/Revised: 1 March 2016/ Accepted: 7 March 2016/Published online: 10 May 2016

(C) The Author(s) 2016. This article is published with open access at Springerlink.com

\begin{abstract}
Chromogranin A (CGA)-N46, a derived peptide of human chromogranin A, has antifungal activity. To further research the active domain of CGA-N46, a series of derivatives were designed by successively deleting amino acid from both terminus of CGA-N46, and the amino acid sequence of each derivative was analyzed by bioinformatic software. Based on the predicted physicochemical properties of the peptides, including half-life time in mammalian reticulocytes (in vitro), yeast (in vivo) and E. coli (in vivo), instability index, aliphatic index and grand average of hydropathicity (GRAVY), the secondary structure, net charge, the distribution of hydrophobic residues and hydrophilic residues, the final derivatives CGA-N15, CGAN16, CGA-N12 and CGA-N8 were synthesized by solidphase peptide synthesis. The results of bioinformatic analysis showed that CGA-N46 and its derivatives were $\alpha$ helix, neutral or weak positive charge, hydrophilic, and CGA-N12 and CGA-N8 were more stable than the other derivatives. The results of circular dichroism confirmed that CGA-N46 and its derived peptides displayed $\alpha$-helical structure in an aqueous solution and $30 \mathrm{mM}$ sodium dodecylsulfate, but $\alpha$-helical contents decreased in hydrophobic lipid vesicles. CGA-N15, CGA-N16, CGAN12 and CGA-N8 had higher antifungal activities than their mother peptide CGA-N46. Among of the derived peptides, CGA-N12 showed the least hemolytic activity. In conclusion, we have successfully identified the active domain of CGA-N46 with strong antifungal activity and
\end{abstract}

Rui-Fang Li

1375098398@qq.com

1 College of Biological Engineering, Henan University of Technology, Zhengzhou 450001, China weak hemolytic activity, which provides the possibility to develop a new class of antibiotics.

Keywords Antifungal peptides $\cdot$ CGA-N46 - Derived peptide $\cdot$ Bioinformatic analysis $\cdot$ Molecular design . Structural analysis $\cdot$ Antifungal activity $\cdot$ Hemolytic activity

\section{Introduction}

Over the past decades, the widespread use of antibiotics has led to the rapid emergence of antibiotic-resistant bacteria $[1,2]$. Antimicrobial peptides (AMPs) exhibit broadspectrum activity against bacteria, fungi, viruses, parasites and even cancer cells. AMPs were recently determined to be potential candidates of conventional antibiotics for treating drug-resistant bacterial infections [3, 4]. These peptides have been isolated from many natural sources including microorganism, insects, animals and plants $[5$, 6]. As of July 2015, the current AMP database contains over 2500 AMPs (http://aps.unmc.edu/AP/main.php) [7].

Chromogranin $\mathrm{A}$ is a soluble protein which exists in endocrine cells and neurons $[8,9]$. The endogenous chromogranin A-derived peptides, such as vasostatin-I and catestatin, have been described to be natural defensive barriers for human body [10, 11]. Vasostatin-I (CGA1-76), an $\mathrm{N}$-terminal fragment of chromogranin $\mathrm{A}$, is able to kill a large variety of fungi and yeast cells in micromolar range [12]. Lugardon group synthesized several derived CGA $\mathrm{N}$-terminal fragments. The results of their antifungal research indicated that the shortest active peptide corresponded to the sequence Arg47-Leu66, and named chromofungin. CGA-N46, a novel antifungal peptide containing the 31 st to 76 th amino acids of human 
chromogranin $\mathrm{A}$, showed strong anti-Candida activity. $\mathrm{Li}$ et al. [13] successfully expressed CGA-N46 in engineered Bacillus subtilis strain DB1342 and optimized the expression and purification protocol. However, the yield and the purity of peptide CGA-N46 still could not meet the demand of research.

Solid-phase peptide synthesis (SPPS) is another method to prepare peptide. Compared with genetic engineering expression, SPPS has many advantages including efficient synthesis, easy purification and high purity. However, the difficulty in maintaining the correct structure and function for synthesized peptides increase with the lengthening of peptides [14].

In this report, in order to further study the antifungal active domain, CGA-N46 was analyzed by bioinformatics software. The potential antifungal-derived fragments were designed. The structures and biological activities of the designed derivatives were further investigated to find the candidates with strong antifungal activities and bio-safety.

\section{Methods}

\subsection{Microorganisms and Reagents}

Candida glabrata (ATCC-90525), Candida parapsilosis (ATCC-20224), Candida krusei (ATCC-6258), Candida tropicalis (ATCC-20240), Candida albicans (ATCC-2048) were supplied by the Chinese Academy of Medical Sciences.

CGA-N46 and its derivatives were synthesized by solidphase peptide synthesis method. Peptide purification was performed using high-performance liquid chromatography (HPLC). The mass of each peptide was confirmed via mass spectrometry. Final purity of the peptides was determined to be $90 \%$ by analytical HPLC.

\subsection{Physicochemical Properties Analysis}

The structural prediction software ProtParam tool in bioinformatics website ExPASy (http://www.expasy.ch/ tools/) was used to predict the physicochemical properties of the peptides, including molecular weight, isoionic point (PI), half-life time in mammalian reticulocytes (in vitro), yeast (in vivo) and E. coli (in vivo), instability index, aliphatic index and GRAVY. Peptide was predicted to be stable when instability index was less than 40. Otherwise, peptide was assumed to be unstable. The heat stability of peptide was indicated by its aliphatic index. The higher aliphatic index means higher heat stability. The hydrophilicity and hydrophobicity of peptide were predicted by GRAVY. The peptide was hydrophobic when the GRAVY value was plus; otherwise, it was hydrophilic.

\subsection{Amino Acid Distribution Analysis}

The Helical Wheel Projections software in web (http:// rzlab.ucr.edu/scripts/wheel/wheel.cgi) was used to predict the distribution of the hydrophobic and hydrophilic residues of the derived peptides.

\subsection{Preparation of Small Unilamellar Lipid Vesicles}

Small unilamellar lipid vesicles (SUV) were prepared according to the method $[15,16]$ with modification. One hundred $\mathrm{mg}$ of phosphatidylcholine (PC): phosphatidylglycerol (PG) (3:1 weight ratio) dissolved in chloroform was dried by rotating evaporation under a vacuum to form a lipid film on the round bottom glass bottle wall. The obtained lipid film, composed of $75 \mathrm{mg}$ of PC and $25 \mathrm{mg}$ of $\mathrm{PG}$, was rehydrated with $10 \mathrm{ml}$ of $20 \mathrm{mM}$ potassium phosphate buffer ( $\mathrm{pH}$ 7.0) to the final lipid concentration of $10 \mathrm{mg} \mathrm{mL}^{-1}$. SUVs were prepared by ultrasonic processing the sample with pulses ' $15 \mathrm{~s}$ on/45 s off' for $10 \mathrm{~min}$ at $4{ }^{\circ} \mathrm{C}$ and an input power of $40 \mathrm{~W}$ until the suspension was transparent. The peptides were added to SUVs at concentrations of $0.25 \mathrm{mg} \mathrm{mL}^{-1}$ and incubated at room temperature for at least $30 \mathrm{~min}$ prior to the measurements.

\subsection{Circular Dichroism Assay}

Circular dichroism (CD) spectroscopy was performed using a MOS-500 spectropolarimeter (Bio-Logic, MOS500, France) with the method according to the report [17] with modest modification. CD spectra of the peptides were recorded between 190 and $240 \mathrm{~nm}$ of scanning spectrum at $1 \mathrm{~nm}$ intervals at $25^{\circ} \mathrm{C}$ with a scanning speed of $100 \mathrm{~nm} \mathrm{~min}{ }^{-1}, 2 \mathrm{~s}$ of response time, $1.0 \mathrm{~nm}$ of step size.

Peptides with a constant concentration of $0.25 \mathrm{mg} \mathrm{mL}^{-1}$ were prepared in three different solvents, $20 \mathrm{mM}$ phosphate buffer, $\mathrm{pH} 7.4$ (mimicking the aqueous environment), $30 \mathrm{mM}$ sodium dodecyl sulfate (SDS, mimicking the negatively charged environment of microbial membrane) and SUVs (mimicking the hydrophobic environment of the microbial membrane). The samples were loaded in a rectangular quartz cuvette with a path length of $1 \mathrm{~mm}$. The spectra of three consecutive scans were averaged and corrected by subtracting the solvent/buffer spectra. The mean residue molar ellipticities were calculated using the equation $\theta=\left(\theta_{\mathrm{obs}} \cdot 1000\right) /(c \cdot l \cdot n)$ [18], where $\theta_{\mathrm{obs}}$ is the ellipticity in millidegrees; $c$ is the peptide concentration in mole $1^{-1} ; l$ is the optical path length of the cuvette in centimeters; and $n$ is the number of peptide residues.

The CD data of CGA-N46 and its derivatives were analyzed by CDPro software package including SELCON, 
CONTIN and CDSSTR to study the conformational changes in CGA-N46 and its derivatives in the aqueous, SDS and SUVs environments.

\subsection{Antifungal Assays}

Minimum inhibitory concentrations (MICs) of CGA-N46 and its derivatives against fungi were measured according to a modified version of broth microdilution method of the Clinical and Laboratory Standards Institute (CLSI) [19]. Fungi cell's viability was assessed based on the reduction of 3-[4,5-dimethylthiazolyl]-2,5-diphenyltetrazolium bromide (MTT) into formazan dye by active mitochondria [20]. Briefly, peptides were serially twofold diluted in $20 \mathrm{mM}$ PBS (pH 6.0) to a final concentration between $2 \mathrm{mg} \mathrm{mL}^{-1}$ and $3.9 \mu \mathrm{g} \mathrm{mL}^{-1}$. Subsequently, $100 \mu \mathrm{L}$ samples was dispensed into the wells of a 96-U-shapedwell plate, and each was mixed with $100 \mu \mathrm{L}$ of the

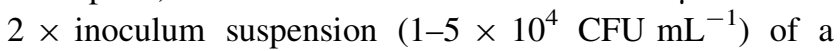
log-phase fungal culture in Sabouraud (SD) broth. Strains without treatment with peptides were used as negative control. The cultures were incubated at $30{ }^{\circ} \mathrm{C}$ without agitation for $16 \mathrm{~h} .10 \mu \mathrm{L}$ of MTT solution $\left(5 \mathrm{mg} \mathrm{mL}^{-1}\right.$ MTT in PBS) was added to each well, and the plate was further incubated for $4 \mathrm{~h}$. After rinsed, $100 \mu \mathrm{L}$ of dimethylsulfoxide (DMSO) was added to dissolve the MTT formazan crystals. The inhibition of growth was determined by measuring the absorbance at $570 \mathrm{~nm}$ with a microplate reader. The relative cellular activity was calculated according to the following formula:

cell survival inhibition rate (\% of control)

$=\left[\left(\mathrm{OD}_{570}\right.\right.$ of the negative sample

$-\mathrm{OD}_{570}$ of the treated sample)

$/ O D_{570}$ of the negative control] $\times 100 \%$.

And the MIC was defined as the lowest peptide concentration that completely inhibited fungal growth.

Each test was performed in triplicate, and the data were expressed as the mean $\pm \mathrm{SE}$.

\subsection{Hemolytic Assay}

Hemolytic activity was tested according to the method [21]. Briefly, peptides were serially twofold diluted using PBS in 96-well plates to give a volume of $100 \mu \mathrm{L}$ of the sample solution in each well, and the final concentration of peptides ranged between $2.0 \mathrm{mg} \mathrm{mL}^{-1}$ and $3.9 \mu \mathrm{g} \mathrm{mL}^{-1}$. Human red blood cells (RBCs) from a healthy volunteer were diluted to a concentration of $2 \%$ in PBS. $100 \mu \mathrm{L}$ of the RBC suspension was added to each well, and the reactions were incubated at $37{ }^{\circ} \mathrm{C}$ for $60 \mathrm{~min}$, followed by
$150 \mu \mathrm{L}$ supernatant being transferred to a new 96-well plate (U-shaped well). The release of hemoglobin was determined by measuring the absorbance of the supernatant at $570 \mathrm{~nm}$. RBCs in PBS and $0.1 \%$ (v/v) Triton-X100 were used as the negative and positive controls, respectively. The percentage of hemolysis was calculated using the following formula:

$$
\begin{aligned}
\text { Hemolysis rate }(\%)= & {\left[\left(\mathrm{OD}_{570}\right.\right. \text { of the treated sample }} \\
& \left.-\mathrm{OD}_{570} \text { of the negative control }\right) \\
& /\left(\mathrm{OD}_{570}\right. \text { of the positive control } \\
& \left.\left.-\mathrm{OD}_{570} \text { of the negative control }\right)\right] \times 100 \% .
\end{aligned}
$$

Each test was performed in triplicate, and the data were expressed as the mean $\pm \mathrm{SE}$.

\subsection{Statistical Analysis}

Experimental data were analyzed using the PASW statistical 18 (SPSS, Inc., Chicago, IL, USA) to perform oneway analysis of variance followed by least significant difference and Duncan's tests. The results are reported as mean \pm standard error of the mean (SEM). Differences between treatment groups and the control group were considered to be statistically significant at $p<0.05$ and extremely significant at $p<0.01$.

\section{Results}

\subsection{Peptide Design and Predicted Physicochemical Properties}

Derived peptides were obtained by successively deleting amino acid from both ends of CGA-N46. The amino acid sequences of the derived peptides were analyzed by software ProtParam tool. The physicochemical properties of CGA-N46 and its derived peptides were predicted and compared. Four potential peptides with long half-life time and high stability were obtained, and were named as CGAN15, CGA-N16, CGA-N12 and CGA-N8. The amino acid sequences are given in Table 1. CGA-N15 is the middle fragment of CGA-N46 with 15 amino acids. CGA-N16 is the C-terminal fragment of CGA-N46. CGA-N12 is a derived fragment of CGA-N16, and CGA-N8 is a derived peptide of CGA-N12.

As given in Table 2, all the derived peptides were near neutral or weak alkaline and hydrophilic. Among of them, CGA-N12 and CGA-N8 had longer half-life time and were more stable than CGA-N15 and CGA-N16. Compared with CGA-N8, the heat stability of CGA-N12 was higher. 
Table 1 Amino acid sequences of CGA-N46 and its derived peptides

\begin{tabular}{ll}
\hline Peptide & Amino acid sequence \\
\hline CGA-N46 & $\mathrm{NH}_{2}$-PMPVSQECFETLRGHERILSILRHQNLLKELQDLALQGAKERAHQQ-COOH \\
CGA-N15 & $\mathrm{NH}_{2}$-ERILSILRHQNLLKE-COOH \\
CGA-N16 & $\mathrm{NH}_{2}$-LQDLALQGAKERAHQQ-COOH \\
CGA-N12 & $\mathrm{NH}_{2}$-ALQGAKERAHQQ-COOH \\
CGA-N8 & $\mathrm{NH}_{2}-$ GAKERAHQ-COOH \\
\hline
\end{tabular}

Table 2 Physicochemical properties of four peptides derived from CGA-N46

\begin{tabular}{lllllllll}
\hline Peptide & Molecular & PI & GRAVY & Half-life & Instability index & Aliphatic index \\
\cline { 5 - 7 } & & & & Mammalian reticulocytes & Yeast & E. coli & \\
\hline CGA-N46 & 5363.1 & 7.38 & -0.674 & $>20 \mathrm{~h}$ & $>20 \mathrm{~h}$ & Unpredicted & 75.91 & 97.16 \\
CGA-N15 & 1862.2 & 8.85 & -0.447 & $1 \mathrm{~h}$ & $30 \mathrm{~min}$ & $>10 \mathrm{~h}$ & 55.03 & 156.0 \\
CGA-N16 & 1806.0 & 6.75 & -1.012 & $5.5 \mathrm{~h}$ & $3 \mathrm{~min}$ & $2 \mathrm{~min}$ & 91.88 & 91.88 \\
CGA-N12 & 1336.4 & 8.8 & -1.400 & $4.4 \mathrm{~h}$ & $>20 \mathrm{~h}$ & $>10 \mathrm{~h}$ & 38.23 & 57.5 \\
CGA-N8 & 895.9 & 8.75 & -1.925 & $30 \mathrm{~h}$ & $>20 \mathrm{~h}$ & $>10 \mathrm{~h}$ & -12.48 & 25 \\
\hline
\end{tabular}

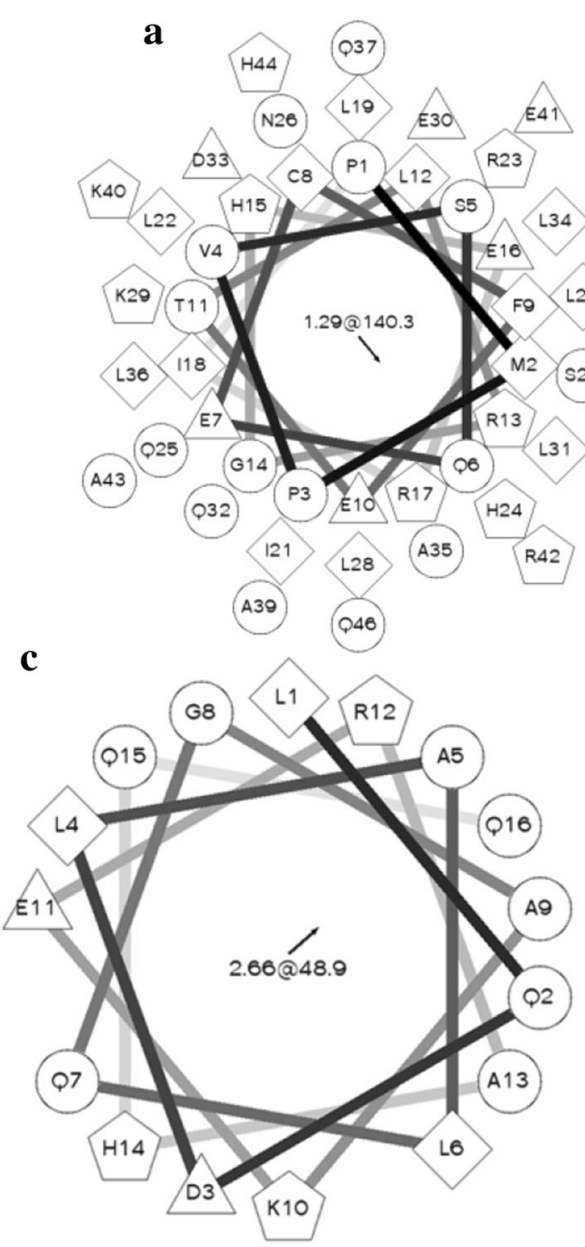

Fig. 1 Predicted amino acid residues distribution of CGA-N46 and its derived peptides. a CGA-N46, b CGA-N15, c CGA-N16, d CGAN12, e CGA-N8. Note Hydrophilic residues present as circles,
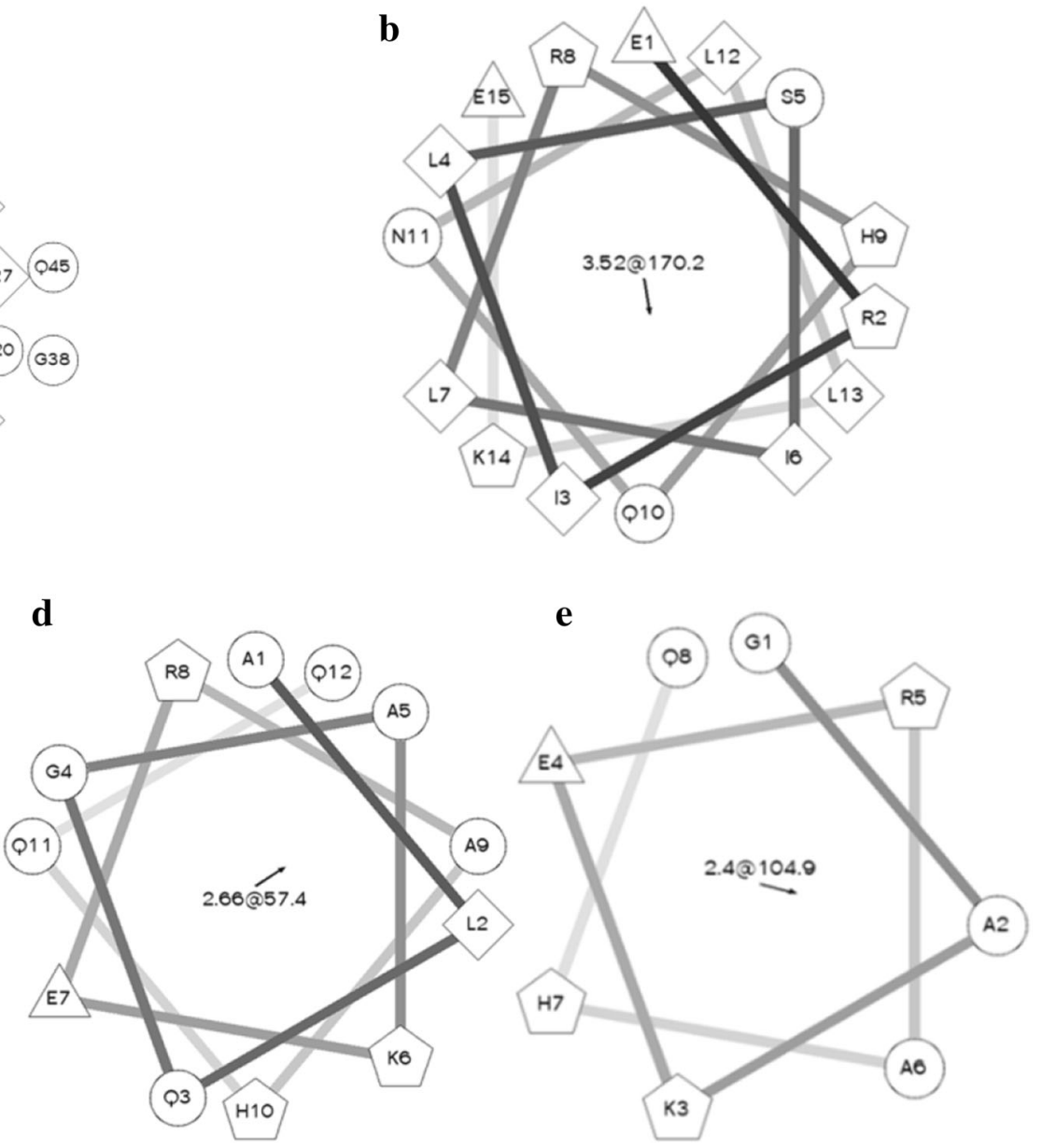

hydrophobic residues as diamonds, potentially negatively charged as triangles and potentially positively charged as pentagons. Figure has been produced by Helical Wheel Projections and Photoshop 


\subsection{Amino Acid Distribution of CGA-N46 and Its Derivatives}

The amino acid sequences of the derived peptides were analyzed by software the Helical Wheel Projections. The amino acid distribution of CGA-N46 derived peptides were predicted as shown in Fig. 1. The results in Fig. 1 indicated that there were no typical hydrophilic face and hydrophobic face in the structure of peptide CGA-N46 and its derivatives. The hydrophobic residues, hydrophilic residues and the residues with positive or negative charges scattered randomly.

CD spectroscopy was performed to research the secondary structure of CGA-N46 and its derivatives peptides in aqueous environment, SDS and SUVs. The CD spectra were analyzed and the mean residue ellipticity is shown in Fig. 2. CGA-N46 and its derived peptides displayed a typical of $\alpha$-helical conformation with characteristic double minima at 208 and $222 \mathrm{~nm}$ [22, 23]. Interestingly, an increase in the mean residue ellipticity at 208 and $222 \mathrm{~nm}$ was observed at the presence of SUVs. The CD spectra difference suggested that the secondary structural alterations of CGA-N46 and its derivatives were promoted when they interacted with cell membranes.

To examine the conformational percentage in the absence and presence of SUVs, the CD data of CGA-N46 and its derivatives were analyzed by CDPro software package including SELCON, CONTIN and CDSSTR. The percentage of secondary structure elements for CGA-N46 and its derived peptides (Table 3) demonstrated that the spectra of CGA-N46 resembled the spectra of its derived peptides in the absence and presence of SUVs; however, their intensity of $\alpha$-helical in SUVs is somewhat lower than that in aqueous conditions, which indicated that hydrophobicity might reduce the content of $\alpha$-helix and promote other folding conformation of CGA-N46 and its derivatives. This result is different from some related reports $[24,27,28]$.
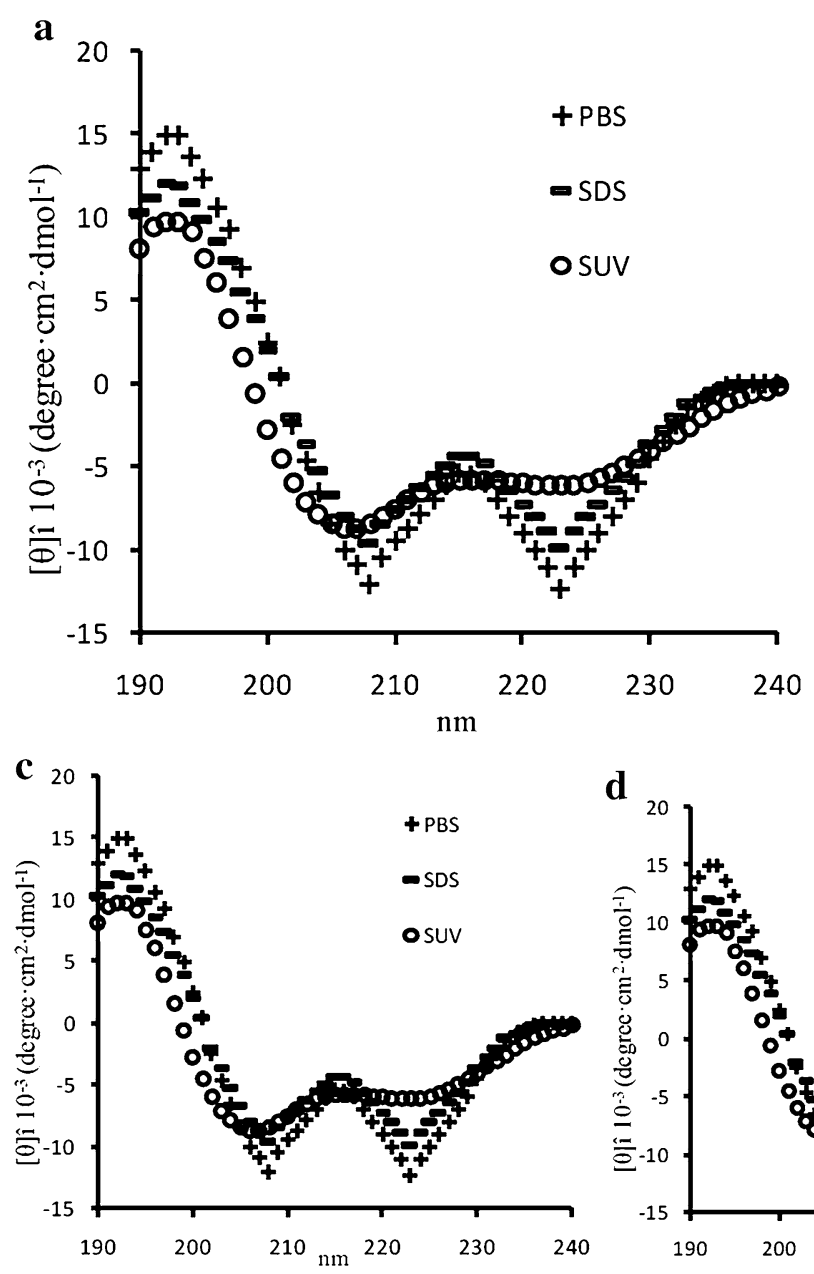

b
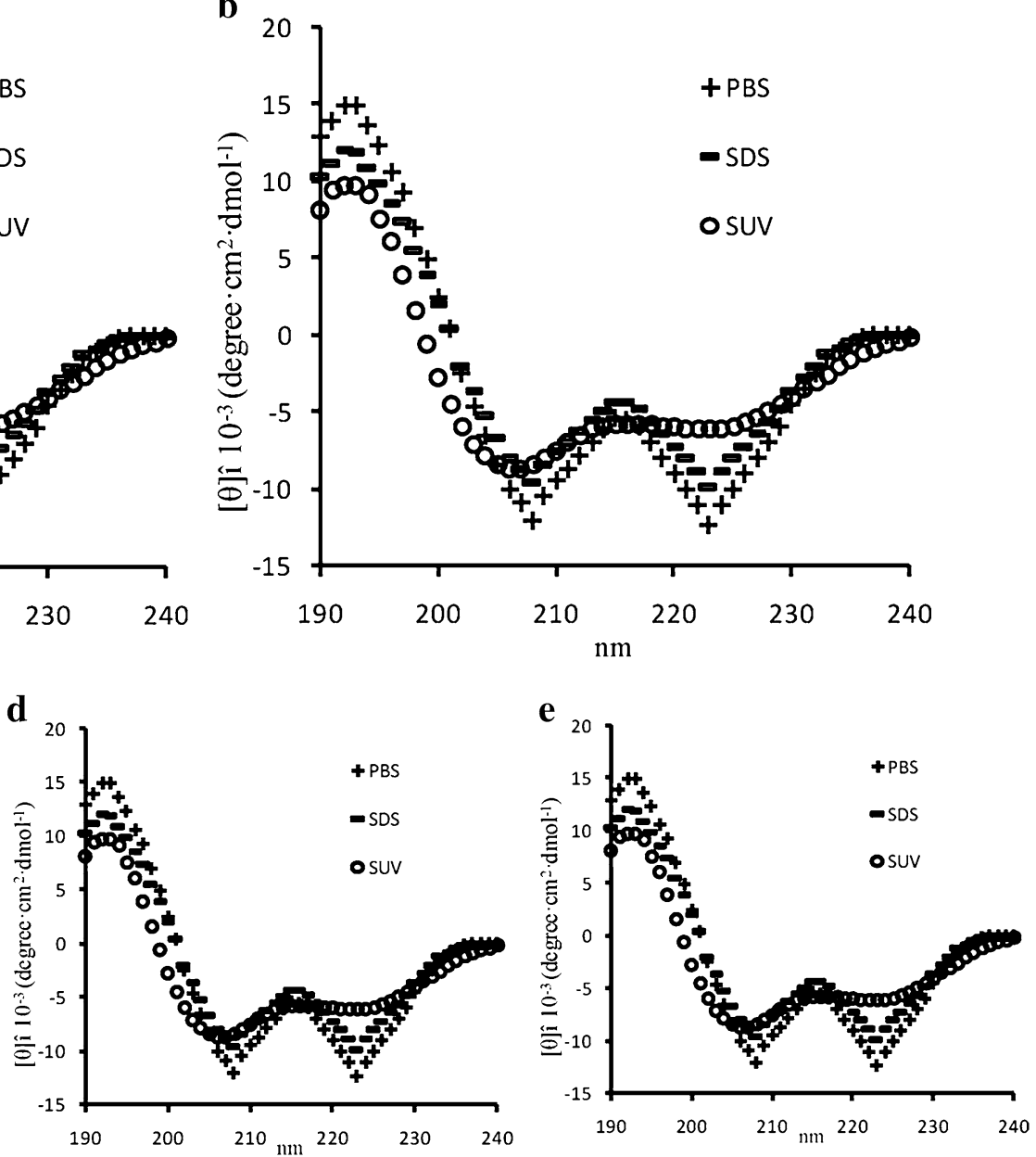

Fig. 2 CD spectra of CGA-N46 and its derived peptides in different solution. a CGA-N46, b CGA-N15, c CGA-N16, d CGA-N12, e CGA-N8. Figure has been produced by Excel and Adobe Illustrator CS6 
Table 3 Percentages of the secondary structural elements of CGA$\mathrm{N} 46$ and its derived peptides

\begin{tabular}{|c|c|c|c|c|}
\hline & $\alpha$-Helix (\%) & $\beta$-Sheet $(\%)$ & $\beta$-Turn $(\%)$ & Random (\%) \\
\hline \multicolumn{5}{|c|}{ CGA-N46 } \\
\hline $\mathrm{H}_{2} \mathrm{O}$ & 79.57 & 15.79 & 3.54 & 1.1 \\
\hline SDS & 80.32 & 14.96 & 2.32 & 2.4 \\
\hline SUV & 38.74 & 25.96 & 22.79 & 12.51 \\
\hline \multicolumn{5}{|c|}{ CGA-N15 } \\
\hline $\mathrm{H}_{2} \mathrm{O}$ & 82.69 & 10.89 & 3.65 & 2.77 \\
\hline SDS & 83.41 & 11.25 & 3.82 & 1.52 \\
\hline SUV & 41.53 & 30.47 & 13.96 & 14.04 \\
\hline \multicolumn{5}{|c|}{ CGA-N16 } \\
\hline $\mathrm{H}_{2} \mathrm{O}$ & 83.67 & 11.16 & 3.23 & 1.94 \\
\hline SDS & 83.33 & 11.43 & 3.36 & 1.88 \\
\hline SUV & 40.91 & 35.67 & 12.59 & 10.83 \\
\hline \multicolumn{5}{|c|}{ CGA-N12 } \\
\hline $\mathrm{H}_{2} \mathrm{O}$ & 88.36 & 8.64 & 1.56 & 1.44 \\
\hline SDS & 87.91 & 9.53 & 1.38 & 1.18 \\
\hline SUV & 43.21 & 32.09 & 15.39 & 9.31 \\
\hline \multicolumn{5}{|c|}{ CGA-N8 } \\
\hline $\mathrm{H}_{2} \mathrm{O}$ & 87.79 & 8.56 & 1.34 & 2.13 \\
\hline SDS & 84.89 & 9.87 & 1.79 & 3.45 \\
\hline SUV & 43.76 & 34.27 & 13.86 & 8.11 \\
\hline
\end{tabular}

\subsection{Antifungal and Hemolytic Activities of CGA- N46 and Its Derived Peptides}

The antifungal activity of CGA-N46 and its derived peptides against several Candida spp. (Table 4) was used as an indicator of the peptide's anti-Candida activity. CGA-N46 and its derived peptides were active against all of the tested yeasts (MICs, less than $0.5 \mathrm{mM}$ ). But interestingly, different yeast exhibited various greatest sensitivity for different peptides: C. krusei (MIC, $0.37 \mathrm{mM}$ ) for CGA-N46, C. tropicalis (MIC, $0.073 \mathrm{mM}$ ) for CGA-N15, C. glabrata (MIC, $0.28 \mathrm{mM}$ ) for CGA-N16, C. tropicalis (MIC, $0.075 \mathrm{mM}$ ) for CGA-N12, and C. krusei and C. albicans (MIC, $0.24 \mathrm{mM}$ ) for CGA-N8. The most sensitive strain $C$. krusei for CGA-N46 changed to be $C$. tropicalis for CGAN15 and CGA-N12.

The hemolytic activity of CGA-N46 and its derived peptides against the highly sensitive human erythrocytes was determined as a measure of its toxicity to mammalian cells. The release of hemoglobin was monitored by measuring the absorbance at $570 \mathrm{~nm}$. As negative and positive controls, erythrocytes in PBS without CGA-N46 and $0.1 \%$ (v/v) Triton X-100 in PBS were employed, respectively. CGA-N46 and CGA-N12 showed weak hemolytic activity at the concentration of MIC. For CGA-N8, the MIC was near the concentration of its $5 \%$ hemolysis. Meanwhile, CGA-N15 and CGA-N16 showed strong hemolytic activity. Comparing the ratio of the $5 \%$ hemolytic concentration with the MIC for the sensitive yeasts, CGA-N12 (5.2fold) is higher than that of CGA-N46 (twofold).

\section{Discussion}

Andreu et al. [25] shortened an antimicrobial peptide with 26 amino acids without losing antimicrobial activity. Park et al. [26] found the antimicrobial buforin I C-terminal with 21 amino acids had stronger antimicrobial activity than parent peptides. In this study, we shortened CGA-N46 to find stronger antifungal-derived peptide with better biological characters based on the bioinformatics analysis and obtained derived fragments CGA-N16, CGA-N15, CGAN12 and CGA-N8.

There were reports that some peptides including clavanin A formed random coil structure in aqueous solution $[17,24,27,28]$. In contrast, peptides folded into certain secondary structures in the presence of trifluoroethanol [27, 28]. van Kan et al. [24] reported that the folding behavior of the peptides in aqueous solution highly depends on the nature of the amino acids. Different from the reports, CGAN46 and its derivatives displayed $\alpha$-helix in aqueous solution and SDS environments, but conformation changed in SUVs.

CGA-N46 and its derived peptides had inhibitory effects on the growth of fungi, but their antifungal activity was

Table 4 MIC and hemolytic activity of CGA-N46 and its derived peptides

\begin{tabular}{lllllll}
\hline Peptide & \multicolumn{2}{l}{ MIC $\left(\mathrm{mmol} \mathrm{L}^{-1}\right)$} & & 5 \% Hemolysis $\left(\mathrm{mmol} \mathrm{L}^{-1}\right)$ \\
\cline { 2 - 6 } & C. glabrata & C. parapsilosis & C. krusei & C. tropicalis & C. albicans & \\
\hline CGA-N15 & 0.11 & 0.13 & 0.13 & 0.073 & 0.13 & 0.031 \\
CGA-N16 & 0.28 & 0.32 & 0.38 & 0.41 & 0.38 & 0.056 \\
CGA-N12 & 0.26 & 0.27 & 0.27 & 0.075 & 0.28 & 0.39 \\
CGA-N8 & 0.3 & 0.3 & 0.24 & 0.29 & 0.24 & 0.27 \\
CGA-N46 & 0.48 & 0.48 & 0.37 & 0.50 & 0.50 & 0.74 \\
\hline
\end{tabular}


different. CGA-N12 was the inner sequence of CGA-N16, which was also the inner sequence of CGA-N46. They shared the same active center. The results of MTT assay suggested that the amount and features of amino acids influenced the antifungal activity of peptides.

As common structural characteristics, AMPs are peptides with net positive charges and adopt amphipathic structures [29]. Three kinds of models, including barrelstave model, toroidal (or worm-hole) model and carpet model, have been proposed how AMPs finally form ion channels, transmembrane pores or extensive membrane rupture. The toroidal model appears to be more consistent with the mechanism of most AMPs [30]. The structure of the AMPs is necessary to lead the AMPs insert into the membrane. The bioinformatics analysis results of CGAN46 and its derived peptides suggested that CGA-N46 and its derived peptides were weak positive charge or neutral, hydrophilic peptides. The results of CD demonstrated that the secondary structure of CGA-N46 and its derived peptides were $\alpha$-helical in PBS and SDS, and they changed with $\alpha$-helix decreasing and $\beta$-sheet, $\beta$-turn and random coil increasing when the solvents changed from PBS to SUVs. The results suggested that CGA-N46 and its derived peptides did not share the similar action mechanism with common $\alpha$-helical AMPs.

As defenders in innate immunity, AMPs select 'killing' microbial without destroying human red cells [31]. Vasostatin-I was supposed to be one of innate immunity factors in mammalian [32]. Our study demonstrated that CGAN12 showed strong antifungal activity and the least hemolytic activity.

\section{Conclusions}

Based on the bioinformatics analysis of CGA-N46, a series of CGA-N46 derivatives were synthesized. The structure, antifungal activities, hemolytic activities were studied. Among the derivatives, CGA-N12 had higher antifungal activity and less hemolytic effect. It would be a potential candidate for further preclinical research.

Acknowledgments This work was supported by the National Science Foundation of China $(31071922,31572264)$ and the Fundamental Research Funds for the Henan Provincial Colleges and Universities in Henan University of Technology (2015RCJH03).

\section{Compliance with Ethical Standards}

Conflict of interest All authors declare no competing financial interests in the findings of this study.

Open Access This article is distributed under the terms of the Creative Commons Attribution 4.0 International License (http://crea tivecommons.org/licenses/by/4.0/), which permits unrestricted use, distribution, and reproduction in any medium, provided you give appropriate credit to the original author(s) and the source, provide a link to the Creative Commons license, and indicate if changes were made.

\section{References}

1. Levy SB, Marshall B (2004) Antibacterial resistance worldwide: causes, challenges and responses. Nat Med 10:S122-S129

2. Zhu X, Zhang L, Wang J, Ma Z, Xu W, Li J, Shan A (2015) Characterization of antimicrobial activity and mechanisms of low amphipathic peptides with different $\alpha$-helical propensity. Acta Biomater 18:155-167

3. Oyston PC, Fox MA, Richards SJ, Clark GC (2009) Novel peptide therapeutics for treatment of infections. J Med Microbiol 58:977-987

4. Mechkarska M, Attoub S, Sulaiman S, Pantic J, Lukic ML, Conlon JM (2014) Anti-cancer, immunoregulatory, and antimicrobial activities of the frog skin host-defense peptides pseudhymenochirin- $1 \mathrm{~Pb}$ and pseudhymenochirin-2Pa. Regul Pept 194-195:69-76

5. Zasloff M (2002) Antimicrobial peptides of multicellular organisms. Nature 415:389-395

6. Radek K, Gallo R (2007) Antimicrobial peptides: natural effectors of the innate immune system. Semin Immunopathol 29:27-43

7. Fosgerau K, Hoffmann T (2015) Peptide therapeutics: current status and future directions. Drug Discov Today 20:122-128

8. Eiden LE (1987) Is chromogranin a prohormone? Nature 325:301

9. Simon JP, Aunis D (1989) Biochemistry of the chromogranin A protein family. Biochem J 262:1-13

10. Radek KA, Lopez-Garcia B, Hupe M, Niesman IR, Elias PM, Taupenot L, Mahata SK, O'Connor DT, Gallo RL (2008) The neuroendocrine peptide catestatin is a cutaneous antimicrobial and induced in the skin after injury. $J$ Invest Dermatol 128:1525-1534

11. Akaddar A, Doderer-Lang C, Marzahn MR, Delalande F, Mousli M, Helle K, Van Dorsselaer A, Aunis D, Dunn BM, Metz-Boutigue MH, Candolfi E (2010) Catestatin, an endogenous chromogranin A-derived peptide, inhibits in vitro growth of Plasmodium falciparum. Cell Mol Life Sci 67:1005-1015

12. Lugardon K, Raffner R, GoumonY Corti A, Delmas A, Bulet P, Aunis D, Metz-Boutigue MH (2000) Antibacterial and antifungal activities of vasostatin-1, the $\mathrm{N}$-terminal fragment of chromogranin A. J Biol Chem 275:10745-10753

13. Li RF, Wang B, Liu S, Chen SH, Yu GH, Yang SY, Huang L, Yin YL, Lu ZF (2015) Optimization of the expression conditions of CGA-N46 in Bacillus subtilis DB1342 (p-3N46) by response surface methodology. Interdiscip Sci Comput Life Sci. doi:10. 1007/s12539-015-0115-x

14. Zinieris N, Zikos C, Ferderigos N (2006) Improved solid-phase peptide synthesis of 'difficult peptides' by altering the microenvironment of the developing sequence. Tetrahedron Lett 47:6861-6864

15. Yang JT, Wu CS, Martinez HM (1986) Calculation of protein conformation from circular dichroism. Methods Enzymol 130:208-269

16. Lemeshko VV (2014) Competitive interactions of amphipathic polycationic peptides and cationic fluorescent probes with lipid membrane: experimental approaches and computational model. Arch Biochem Biophys 545:167-178

17. Lv Y, Wang J, Gao H, Wang Z, Dong N, Ma Q, Shan A (2014) Antimicrobial properties and membrane-active mechanism of a potential $\alpha$-helical antimicrobial derived from cathelicidin PMAP-36. PLoS ONE 9:e86364 
18. Chen Y, Mant CT, Farmer SW, Hancock RE, Vasil ML, Hodges RS (2005) Rational design of alpha-helical antimicrobial peptides with enhanced activities and specificity/therapeutic index. J Biol Chem 280:12316-12329

19. Clinical and Laboratory Standards Institute (CLSI) (2008) Reference method for broth dilution antifungal susceptibility testing of yeasts; approved standard-3rd edn. CLSI document M27-A3 (ISBN 1-56238-666-2). Clinical and Laboratory Standards Institute, 940 West Valley Road, Suite 1400, Wayne, Pennsylvania 19087-1898 USA

20. Aleinein RA, Hamoud R, Schäfer H, Wink M (2013) Molecular cloning and expression of ranalexin, a bioactive antimicrobial peptide from Rana catesbeiana in Escherichia coli and assessments of its biological activities. Appl Microbiol Biotechnol 97:3535-3543

21. Wade JD, Lin F, Hossain MA, Dawson RM (2012) Chemical synthesis and biological evaluation of an antimicrobial peptide gonococcal growth inhibitor. Amino Acids 43:2279-2283

22. Chen YH, Yang JT, Martinez HM (1972) Determination of the secondary structures of proteins by circular dichroism and optical rotatory dispersion. Biochemistry 11:4120-4131

23. Johnson WC Jr (1990) Protein secondary structure and circular dichroism: a practical guide. Proteins 7:205-214

24. van Kan EJ, Demel RA, van der Bent A, de Kruijff B (2003) The role of the abundant phenylalanines in the mode of action of the antimicrobial peptide clavanin. Biochim Biophys Acta 1615:84-92

25. Andreu D, Ubach J, Boman A, Wåhlin B, Wade D, Merrifield RB, Boman HG (1992) Shortened cecropin A-melittin hybrids significant size reduction retains potent antibiotic activity. FEBS Lett 296:190-194

26. Park CB, Kim MS, Kim SC (1996) A novel antimicrobial peptide from Bufo bufo gargarizans. Biochem Biophys Res Commun 218:408-413

27. Huang J, Hao D, Chen Y, Xu Y, Tan J, Huang Y, Li F, Chen Y (2011) Inhibitory effects and mechanisms of physiological conditions on the activity of enantiomeric forms of an $\alpha$-helical antibacterial peptide against bacteria. Peptides 32:1488-1495

28. Shang D, SunY Wang C, Wei S, Ma L, Sun L (2012) Membrane interaction and antibacterial properties of chensinin-1, an antimicrobial peptide with a typical structural features from the skin of Rana chensinensis. Appl Microbiol Biotechnol 96:1551-1560

29. Wiesner J, Vilcinskas A (2010) Antimicrobial peptides: the ancient arm of the human immune system. Virulence 1:440-464

30. Brogden KA (2005) Antimicrobial peptides: pore formers or metabolic inhibitors in bacteria? Nat Rev Microbiol 3:238-250

31. Matsuzaki K (2009) Control of cell selectivity of antimicrobial peptides. Biochim Biophys Acta 1788:1687-1692

32. Schneider F, Bach C, Chung H, Crippa L, Lavaux T, Bollaert PE, Wolff M, Corti A, Launoy A, Delabranche X, Lavigne T, Meyer N, Garnero P, Metz-Boutigue MH (2012) Vasostatin-I, a chromogranin A-derived peptide, in non-selected critically ill patients: distribution, kinetics, and prognostic significance. Intensive Care Med 38:1514-1522 